\title{
Radiographic evaluation of posterior selective thoracolumbar or lumbar fusion for moderate Lenke $5 \mathrm{C}$ curves
}

\author{
Yanbin Zhang ${ }^{1} \cdot$ Guanfeng Lin $^{1} \cdot$ Jianguo Zhang ${ }^{1} \cdot$ Jianwei Guo $^{1} \cdot$ \\ Shengru Wang ${ }^{1} \cdot$ Yang Yang $^{1} \cdot$ Jianxiong Shen $^{1} \cdot$ Yipeng Wang $^{1}$
}

Received: 9 May 2016/Published online: 21 September 2016

(c) The Author(s) 2016. This article is published with open access at Springerlink.com

\begin{abstract}
Introduction Posterior selective thoracolumbar or lumbar (TL/L) fusion with pedicle screw constructs for adolescent idiopathic scoliosis (AIS) has been studied in a few researches. However, few studies have discussed the indication for selective TL/L fusion and the behaviors of its adjacent disc angle. The present study aims to discuss the indication for posterior selective TL/L fusion and the behavior of the adjacent disc angle.

Methods 45 consecutive cases of AIS undergoing posterior selective TL/L fusion were retrospectively evaluated, with an average follow-up of 36 months. Radiographs were reviewed to determine the coronal curve magnitude and the sagittal alignment preoperatively, postoperatively and at final follow-up. Thoracic curves in groups A had a correction loss of more than $5^{\circ}$, while thoracic curves in group B had a correction loss of not more than $5^{\circ}$.

Results The coronal curve magnitude of the TL/L curve averaged $44^{\circ}$ preoperatively and it was corrected to $6^{\circ}$ immediately with a correction rate of $84.8 \%$. At final follow-up it was $9^{\circ}$ with a correction loss of $3^{\circ}$. The minor thoracic curve was $26^{\circ}$ preoperatively, and the convex side bending curve magnitude averaged $8^{\circ}$ with a flexibility of $72.7 \%$. It was corrected to $13^{\circ}$ immediately with a spontaneous correction of $48.5 \%$. At final follow-up it was $14^{\circ}$ with a correction loss of $1^{\circ}$. UIVA decreased from $4^{\circ}$ to $2^{\circ}$ after surgery, and it was $2^{\circ}$ at final follow-up. LIVA
\end{abstract}

G. Lin should be regarded as co-first authors.

Jianguo Zhang

jgzhang_pumch@yahoo.com

1 Department of Orthopedics, Peking Union Medical College Hospital, 1 Shuai Fu Yuan, Beijing 100730, People's Republic of China decreased from $7^{\circ}$ to $4^{\circ}$ after surgery, and it was $5^{\circ}$ at final follow-up. Maximal correction of TL/L curves in group A is significantly less than that in group B. 1 patient received revision surgery to fuse the progressive thoracic curve. Conclusion Posterior selective TL/L fusion with pedicle screw constructs allows for spontaneous thoracic correction and maintains coronal and sagittal balance during the follow-up. Maximal correction instead of undercorrection was recommended for moderate Lenke 5C curves. Disc wedging could be improved after surgery and well maintained during the follow-up.

Keywords Selective fusion - Thoracolumbar or lumbar . Indication - Maximal correction - Disc wedging

\section{Introduction}

The goal of corrective surgery in adolescent idiopathic scoliosis (AIS) is to achieve global spinal balance with optimal coronal and sagittal alignment and axial derotation, while sparing motion segments. Sparing motion segments and saving motion capability of the spine have becoming the most controversial part of surgical correction. Since the spread of selective thoracic fusion [1-3], selective thoracolumbar or lumbar (TL/L) fusion drew spine surgeons' attention. There are a few studies on anterior or posterior selective TL/L fusion for Lenke 5C curves [4-6]. The possible advantages of anterior approach may include better visualization, the less demanding nature of the technique, less fusion segments and better inter-body fusion than posterior approach [4, 5, 7]. Issues with the anterior approach included instrumentation failure, pseudarthrosis, and a kyphogenic compression mechanism $[8,9]$. With the wide application of the pedicle screw 
constructs, most spine surgeons preferred to perform posterior-only procedure with better curve correction, less loss of correction over time, and shorter hospital stays [5]. Posterior selective TL/L fusion is becoming widely accepted as a preferred treatment for AIS with structural TL/L curve and compensatory thoracic curve (Lenke 5C). We retrospectively investigated patients treated with posterior selective TL/L fusion to discuss the indication for selective TL/L fusion and radiographic features like the behavior of the adjacent disc angle.

\section{Materials and methods}

After the approval of the institutional review board of the hospital, 45 patients of Lenke 5C AIS with TL/L curvature and minor thoracic curve were identified in a single institution for the time periods from January 2006 to December 2012, with an average follow-up of 36 months (range 24-105 months). Radiographs, clinical charts, and operative reports were reviewed. Criteria for Lenke 5C classification [10] were used, and confirmed with another independent physician examiner familiar with this classification. Specifically, a Lenke 5 curve can be defined as an idiopathic structural curve with the apex from the T12 body to the L4 body. The main thoracic and upper thoracic curves were nonstructural, which means that their magnitude is less than the primary structural curve, they bent out to be less than $25^{\circ}$ on convex side bending radiographs, and no sagittal kyphosis criteria were met (T10-L2 and T2-T5 are less than $20^{\circ}$ ). Exclusion criteria were: age $>20$, nonidiopathic curve, follow-up $<2$ years, incomplete followup materials and poor radiographic images to measure.

\section{Surgical technique}

The patient was placed prone on a radiolucent spinal frame after administering intubated general anesthesia. After surgical exposure, pedicle screws were placed with free hand technique. Once the screws were in place, intraosseous placement was confirmed via $\mathrm{C}$-arm image intensifier. Posterior release were performed where was needed. The convex rod was placed first in all patients. Curve correction was achieved with direct apical vertebral body derotation (VBD), rod rotation and compression and/or distraction. Decortication of the posterior elements was performed and followed by bone graft finally. Sensory- and motor-evoked potentials were used intraoperatively.

\section{Radiographic parameters}

Radiographic analysis included various parameters on the preoperative, immediate postoperative (within 2 weeks), and final follow-up radiographs. Curve magnitudes of thoracic and TL/L curves were measured on both longstanding AP films and supine side bending films. The radiograph measurements and analysis were performed by two individual investigators. We presumed the Cobb angle to be reliably measured to be within $5^{\circ}$. Flexibilities of both curves were calculated. The coronal global balance was defined as the horizontal distance between the $\mathrm{C} 7$ plumb line (C7PL) and the central sacral vertical line (CSVL). The Apical Vertebral Translation (AVT) was measured as the distance between the center of the apical vertebra and C7PL in thoracic curve or CSVL in TL/L curve. Lower instrumented vertebra (LIV) Tilt measured the inclination in degrees of the inferior endplate of the LIV to the horizontal plane. The horizontal plane was defined as the plane perpendicular to the long axis of the radiograph. The coronal lowest instrumented vertebra disc angle (LIVA) immediately below the LIV was measured as the angulation in degrees of the inferior endplate of the lower instrumented vertebra (LIV) relative to the superior endplate of the next caudal vertebra. The coronal upper instrumented vertebra disc angle (UIVA) immediately above the upper instrumented vertebra (UIV) was measured as the angulation in degrees of the upper endplate of the UIV relative to the lower endplate of upper adjacent vertebra. Sagittal curve magnitude was measured as follows: (1) T5-T12; (2) T10-L2; (3) L1-S1. UIVA and LIVA were also measured in the sagittal plane.

Potential errors may occur while measuring the angles on the radiograph (measurement error). This error has been investigated intensively and is suggested to be around $\pm 5^{\circ}$ $[11,12]$. Most investigators have considered $5^{\circ}$ of change or more to be clinically important [13-15], and in clinical setting, it is common for practitioners to make recommendations concerning treatment on the basis of an increase in the curve of $5^{\circ}$ between two successive radiographs [12]. Based on above findings, if correction loss of the thoracic curve is more than $5^{\circ}$, we divided all cases into two groups. Thoracic curves in groups A had a correction loss of more than $5^{\circ}$, while thoracic curves in group B had a correction loss of not more than $5^{\circ}$. We compared the differences of immediate TL/L curve magnitude between two groups.

We calculated overall summary statistics in terms of means and SDs for continuous variables and frequencies for categorical. After the descriptive analysis, $p$ value was calculated using independent sample $t$ tests for continuous variables obeying normal distribution. For those not obeying normal distribution, non-parametric tests were used. We evaluated group differences for categorical variables using Chi-square or Fisher's exact test. All analyses were performed using SPSS (version 17.0.0, Inc. Polar Engineering and Consulting). 


\section{Results}

Patients list is shown in Table 1 . The coronal curve magnitude of the TL/L curve averaged $44^{\circ}$ (range $35^{\circ}-72^{\circ}$ ) preoperatively and it was corrected to $6^{\circ}$ (range $0^{\circ}-22^{\circ}$ ) immediately with a correction rate of $84.8 \%$ (range $47-100 \%$ ). At final follow-up it was $9^{\circ}$ (range $0^{\circ}-28^{\circ}$ ) with a correction loss of $3^{\circ}\left(\right.$ range $\left.0^{\circ}-14^{\circ}\right)$. The minor thoracic curve was $26^{\circ}$ (range $10^{\circ}-43^{\circ}$ ) preoperatively, and the convex side bending curve magnitude averaged $8^{\circ}$ (range $0^{\circ}-18^{\circ}$ ) with a flexibility of $72.7 \%$ (range $28-160 \%$ ). It was corrected to $13^{\circ}$ (range $1^{\circ}-30^{\circ}$ ) immediately with a spontaneous correction of $48.5 \%$ (range $4.3-95.4 \%)$. At final follow-up it was $14^{\circ}$ (range $0^{\circ}-32^{\circ}$ ) with a correction loss of $1^{\circ}\left(\right.$ range $\left.0^{\circ}-13^{\circ}\right)$. Typical case is shown in Fig. 1. Coronal global balance was $21.3 \mathrm{~mm}$ (range 0-47 mm) preoperatively, $19.5 \mathrm{~mm}$ (range 0-43 $\mathrm{mm}$ ) postoperatively and $10.9 \mathrm{~mm}$ (range $0-35 \mathrm{~mm}$ ) at final follow-up. LIV tilt was corrected from $22^{\circ}$ (range $10^{\circ}-36^{\circ}$ ) to $4^{\circ}$ (range $0^{\circ}-18^{\circ}$ ), and at final follow-up it was $4^{\circ}\left(\right.$ range $\left.0^{\circ}-10^{\circ}\right)$. UIVA decreased from $4^{\circ}\left(\right.$ range $\left.0^{\circ}-10^{\circ}\right)$ to $2^{\circ}$ (range $0^{\circ}-7^{\circ}$ ) after surgery, and it was $2^{\circ}$ (range $0^{\circ}-$ $8^{\circ}$ ) at final follow-up. LIVA decreased from $7^{\circ}$ (range $0^{\circ}-$ $18^{\circ}$ ) to $4^{\circ}\left(\right.$ range $0^{\circ}-8^{\circ}$ ) after surgery, and it was $5^{\circ}$ (range $0^{\circ}-18^{\circ}$ ) at final follow-up (Table 2).

For sagittal plane, curve magnitude from T5 to T12 was $18^{\circ}$ (range $4^{\circ}-45^{\circ}$ ) preoperatively, $24^{\circ}$ (range $4^{\circ}-36^{\circ}$ ) postoperatively and $28^{\circ}$ (range $4^{\circ}-58^{\circ}$ ) at final follow-up. Thoracolumbar junction (T10-L2) was $8^{\circ}$ (range $0^{\circ}-40^{\circ}$ ) preoperatively, $5^{\circ}$ (range $0^{\circ}-12^{\circ}$ ) postoperatively and $7^{\circ}$ (range $0^{\circ}-20^{\circ}$ ), and $\mathrm{L} 1-\mathrm{S} 1$ was $53^{\circ}$ (range $29^{\circ}-76^{\circ}$ ) preoperatively, $56^{\circ}$ (range $28^{\circ}-85^{\circ}$ ) postoperatively and $59^{\circ}$ (range $43^{\circ}-86^{\circ}$ ) at final follow-up (Table 3 ).

We found that when maximal correction was defined as that the immediate TL/L curve magnitude was less than $10^{\circ}$, number of $\mathrm{TL} / \mathrm{L}$ maximal correction in group $\mathrm{A}$ is significantly less than that in group B $(p=0.014)$ (Table 4).

\section{Complications and revision surgeries}

Of all the 45 patients, only 1 patient received revision surgery to fuse the progressive thoracic curve. There was no neurologic complication or sign of pseudarthrosis on final follow-up radiographs.

\section{Discussion}

Corrective surgery in adolescent idiopathic scoliosis (AIS) aims to achieve global spinal balance with optimal coronal and sagittal alignment and axial derotation. Selective TL/L fusion drew spine surgeons' attention. Although anterior selective TL/L fusion has several advantages, most spine surgeons preferred to perform posterior-only procedures with the wide application of the pedicle screw constructs. Posterior selective TL/L fusion is becoming widely accepted as a preferred treatment for Lenke 5C curves (structural TL/L curve and compensatory thoracic curve).

Sanders et al. [16] suggested that the surgical success of selective anterior TL/L fusion depended on the structural changes in thoracic curve and the patient's maturity. They stated that patients with closed triradiate cartilages, TL/L:T Cobb ratio more than 1.25 and thoracic curve magnitude on convex side bending film $\leq 25^{\circ}$ would have satisfactory results. Oglivie et al. [17] stated the indications of selective $\mathrm{TL} / \mathrm{L}$ fusion for double curves were the minor compensatory thoracic curve $\leq 40^{\circ}$, supple enough and no cosmetic deformity. Posterior procedure with pedicle screw constructs has powerful three-column corrective force and total different influence on the spine. Although there are several researches on posterior selective TL/L fusion with pedicle screw constructs, few of them have stated the indication for selective TL/L fusion. Lark et al. [18] found that Scoliosis Research Society Questionnaire scores and clinical balance are not significantly different between a matched set of patients that had either a selective or nonselective fusion of their Lenke 5 curve at 2 years postoperatively, but they did not discuss when selective TL/L fusion would be performed. Li et al. [19] suggested that patients with a preoperative thoracic curve $>30^{\circ}$ and a preoperative thoracic curve on bending $>20^{\circ}$ may not benefit from selective posterior fusion. In most conditions, when selective TL/L fusion would be performed depended on experiences of surgeons. In present study, out of 45 cases, the curve magnitude ratio of TL/L:T was more than 1.25 in 44 cases. The thoracic curve magnitude was not more than $40^{\circ}$ except 1 case $\left(43^{\circ}\right)$ and all thoracic curve magnitudes on convex side bending films were less than $25^{\circ}$. Posterior selective TL/L fusion achieved $78.9 \%$ correction for the TL/L curve and $44.7 \%$ spontaneous correction for the minor thoracic curve immediately. At final follow-up, there is a correction loss of only $2.7^{\circ}$ and $1^{\circ}$, respectively. Coronal balance was significantly improved and sagittal contours were well maintained with thoracic kyphosis increased a little but within normal range, at final follow-up (Tables 2,3). It turned out to be an effective treatment for patients with Lenke 5C. In 1 case, the preoperative thoracic curve is $43^{\circ}$, its curve magnitude ratio of TL/L:T was 1.18 , and thoracolumbar junction was $22^{\circ}$. Posterior selective TL/LT fusion was performed and the unfused thoracic curve was $21^{\circ}$ at first erect. 30 months after surgery, the unfused thoracic curve progressed to $32^{\circ}$ with cosmetic deformity. A revision surgery was indicated. Based on above data, we recommended thoracic curve magnitude $\leq 40^{\circ}$, convex bending curve magnitude $<25^{\circ}$ 
Table 1 Patient characteristics and preoperative curve parameters

\begin{tabular}{|c|c|c|c|c|c|c|c|c|}
\hline No. & Sex & Age & Follow-up & $\mathrm{TL} / \mathrm{L}$ mag & Thoracic mag & Thoracic flexibility (\%) & Lenke & Cobbs R (TL/L: T) \\
\hline 1 & $\mathrm{~F}$ & 14 & 105 & 45 & 20 & 85.00 & $5 \mathrm{C}$ & 2.25 \\
\hline 2 & $\mathrm{~F}$ & 20 & 100 & 30 & 20 & 95.00 & $5 \mathrm{C}$ & 1.5 \\
\hline 3 & $\mathrm{~F}$ & 13 & 32 & 46 & 32 & 62.50 & $5 \mathrm{C}$ & 1.43 \\
\hline 4 & $\mathrm{~F}$ & 12 & 78 & 36 & 28 & 100.00 & $5 \mathrm{C}$ & 1.28 \\
\hline 5 & M & 13 & 48 & 57 & 24 & 91.67 & $5 \mathrm{C}$ & 2.34 \\
\hline 6 & $\mathrm{~F}$ & 13 & 45 & 44 & 30 & 90.00 & $5 \mathrm{C}$ & 1.46 \\
\hline 7 & $\mathrm{~F}$ & 19 & 64 & 54 & 34 & 64.70 & $5 \mathrm{C}$ & 1.58 \\
\hline 8 & $\mathrm{~F}$ & 15 & 30 & 35 & 24 & 62.50 & $5 \mathrm{C}$ & 1.46 \\
\hline 9 & $\mathrm{~F}$ & 14 & 72 & 36 & 23 & 75.00 & $5 \mathrm{C}$ & 1.56 \\
\hline 10 & $\mathrm{~F}$ & 14 & 72 & 41 & 30 & 53.33 & $5 \mathrm{C}$ & 1.37 \\
\hline 11 & $\mathrm{~F}$ & 16 & 24 & 36 & 16 & 68.75 & $5 \mathrm{C}$ & 2.25 \\
\hline 12 & $\mathrm{~F}$ & 15 & 60 & 49 & 32 & 62.50 & $5 \mathrm{C}$ & 1.53 \\
\hline 13 & $\mathrm{~F}$ & 17 & 24 & 32 & 20 & 95.00 & $5 \mathrm{C}$ & 2.25 \\
\hline 14 & $\mathrm{~F}$ & 13 & 29 & 56 & 22 & 54.54 & $5 \mathrm{C}$ & 2.54 \\
\hline 15 & $\mathrm{M}$ & 12 & 26 & 66 & 23 & 91.30 & $5 \mathrm{C}$ & 2.87 \\
\hline 16 & $\mathrm{~F}$ & 13 & 38 & 28 & 10 & 160.00 & $5 \mathrm{C}$ & 2.8 \\
\hline 17 & $\mathrm{~F}$ & 16 & 38 & 38 & 20 & 65.00 & $5 \mathrm{C}$ & 1.9 \\
\hline 18 & $\mathrm{~F}$ & 19 & 28 & 42 & 22 & 77.27 & $5 \mathrm{C}$ & 1.91 \\
\hline 19 & $\mathrm{~F}$ & 13 & 24 & 50 & 33 & 48.45 & $5 \mathrm{C}$ & 1.51 \\
\hline 20 & $\mathrm{~F}$ & 14 & 24 & 45 & 24 & 87.50 & $5 \mathrm{C}$ & 1.87 \\
\hline 21 & $\mathrm{~F}$ & 15 & 24 & 46 & 35 & 85.71 & $5 \mathrm{C}$ & 1.31 \\
\hline 22 & $\mathrm{~F}$ & 14 & 30 & 51 & 33 & 60.60 & $5 \mathrm{C}$ & 1.54 \\
\hline 23 & $\mathrm{~F}$ & 14 & 50 & 33 & 21 & 33.33 & $5 \mathrm{C}$ & 1.57 \\
\hline 24 & $\mathrm{~F}$ & 16 & 24 & 40 & 28 & 35.71 & $5 \mathrm{C}$ & 1.43 \\
\hline 25 & $\mathrm{~F}$ & 16 & 43 & 40 & 23 & 56.52 & $5 \mathrm{C}$ & 1.74 \\
\hline 26 & $\mathrm{~F}$ & 14 & 24 & 36 & 25 & 36.00 & $5 \mathrm{C}$ & 1.44 \\
\hline 27 & $\mathrm{~F}$ & 19 & 24 & 30 & 16 & 75.00 & $5 \mathrm{C}$ & 1.87 \\
\hline 28 & $\mathrm{~F}$ & 13 & 32 & 51 & 43 & 57.50 & $5 \mathrm{C}$ & 1.18 \\
\hline 29 & $\mathrm{~F}$ & 15 & 36 & 72 & 36 & 88.88 & $5 \mathrm{C}$ & 2 \\
\hline 30 & $\mathrm{~F}$ & 15 & 24 & 46 & 25 & 28.00 & $5 \mathrm{C}$ & 1.84 \\
\hline 31 & $\mathrm{~F}$ & 19 & 24 & 50 & 13 & 69.23 & $5 \mathrm{C}$ & 3.85 \\
\hline 32 & $\mathrm{~F}$ & 17 & 24 & 34 & 22 & 77.25 & $5 \mathrm{C}$ & 1.54 \\
\hline 33 & $\mathrm{~F}$ & 12 & 24 & 42 & 30 & 73.33 & $5 \mathrm{C}$ & 1.4 \\
\hline 34 & M & 16 & 24 & 69 & 40 & 86.04 & $5 \mathrm{C}$ & 1.6 \\
\hline 35 & $\mathrm{~F}$ & 12 & 26 & 40 & 32 & 90.60 & $5 \mathrm{C}$ & 1.25 \\
\hline 36 & $\mathrm{~F}$ & 14 & 26 & 58 & 39 & 64.10 & $5 \mathrm{C}$ & 1.48 \\
\hline 37 & $\mathrm{~F}$ & 19 & 24 & 46 & 34 & 65.62 & $5 \mathrm{C}$ & 1.35 \\
\hline 38 & $\mathrm{M}$ & 16 & 24 & 41 & 26 & 96.15 & $5 \mathrm{C}$ & 1.57 \\
\hline 39 & $\mathrm{~F}$ & 16 & 24 & 45 & 20 & 93.33 & $5 \mathrm{C}$ & 2.25 \\
\hline 40 & $\mathrm{~F}$ & 15 & 24 & 29 & 20 & 80.00 & $5 \mathrm{C}$ & 1.45 \\
\hline 41 & $\mathrm{~F}$ & 14 & 24 & 35 & 26 & 92.30 & $5 \mathrm{C}$ & 1.35 \\
\hline 42 & $\mathrm{~F}$ & 13 & 24 & 35 & 13 & 76.92 & $5 \mathrm{C}$ & 2.69 \\
\hline 43 & $\mathrm{~F}$ & 13 & 24 & 39 & 20 & 70.00 & $5 \mathrm{C}$ & 1.95 \\
\hline 44 & $\mathrm{~F}$ & 15 & 24 & 50 & 32 & 43.75 & $5 \mathrm{C}$ & 1.56 \\
\hline 45 & $\mathrm{~F}$ & 15 & 24 & 44 & 20 & 45.00 & $5 \mathrm{C}$ & 2.2 \\
\hline
\end{tabular}

$\overline{T L / L}$ mag thoracolumbar or lumbar curve magnitude, thoracic mag thoracic curve magnitude, mag $R(T L / L: T)$ curve magnitude ratio of thoracolumbar or lumbar:thoracic 


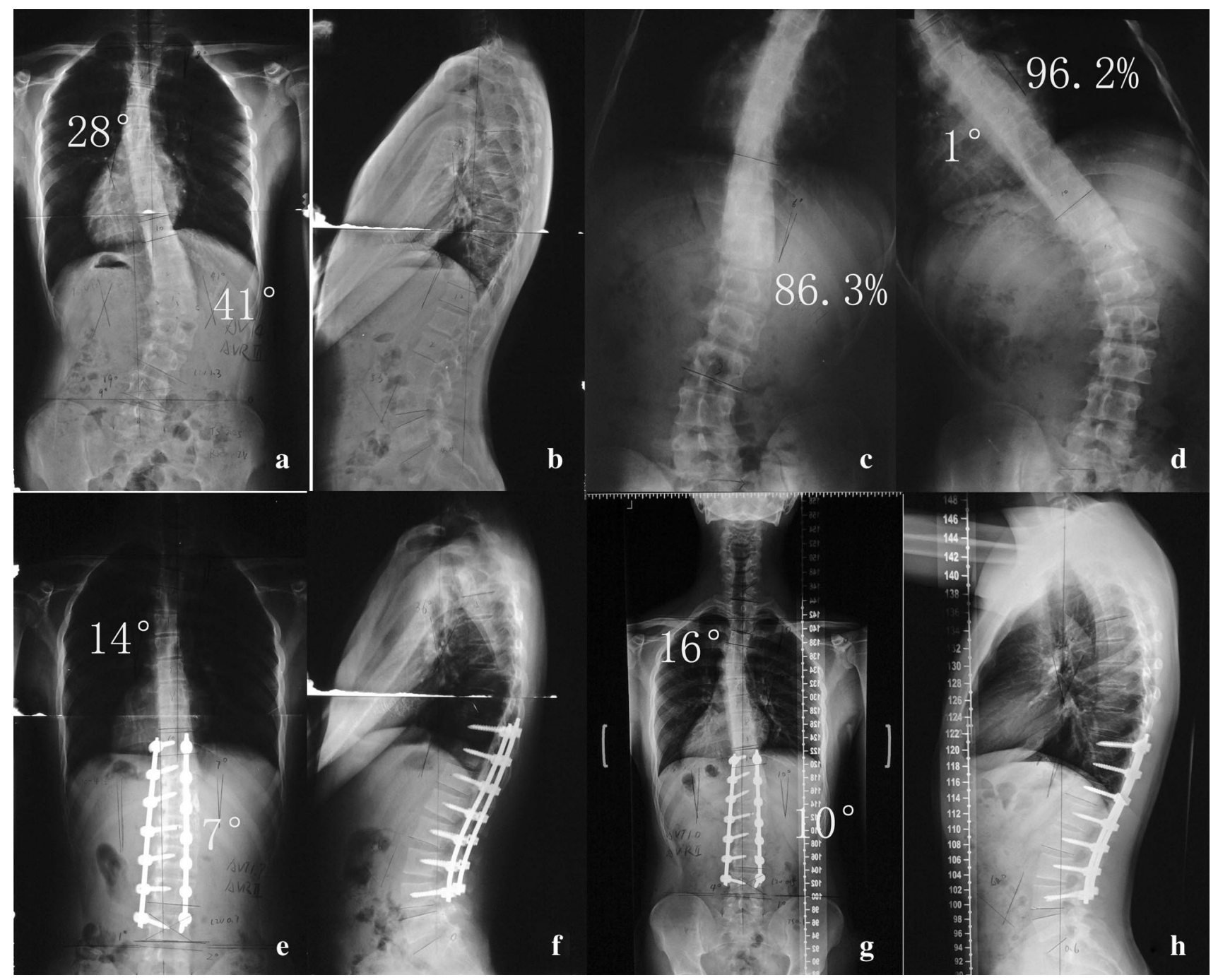

Fig. 1 a-h A 14-year-old female patient. Flexibility of the thoracic and TL/L curve was calculated as $96.2 \%$ and $86.3 \%$, respectively (c, d). After selective fusion, the thoracic curve spontaneously corrected from $28^{\circ}(\mathbf{a}, \mathbf{b})$ to $14^{\circ}(\mathbf{e}, \mathbf{f})$. At final follow-up, it was $16^{\circ}$, with a correction loss of $2^{\circ}(\mathbf{g}, \mathbf{h})$. Coronal and sagittal balances were well maintained both in the immediate post-operation and final follow-up
Table 2 Comparison of preoperative, postoperative and final follow-up coronal measurements

\begin{tabular}{lcccc}
\hline Parameter & Pre-op & Post-op & Follow-up & $p$ \\
\hline TL/L $\left(^{\circ}\right)$ & $44 \pm 7$ & $6 \pm 5$ & $9 \pm 5$ & $<0.01^{*}$ \\
Thoracic $\left({ }^{\circ}\right)$ & $26 \pm 7$ & $13 \pm 7$ & $14 \pm 8$ & $<0.01^{*}$ \\
GCB $(\mathrm{mm})$ & $21.3 \pm 11.5$ & $19.5 \pm 13.3$ & $10.9 \pm 8.9$ & $<0.01^{*}$ \\
AVT $(\mathrm{TL} / \mathrm{L})(\mathrm{mm})$ & $42.5 \pm 12$ & $12.9 \pm 8.4$ & $11.1 \pm 8.8$ & $<0.01^{*}$ \\
AVT $(\mathrm{T})(\mathrm{mm})$ & $12.6 \pm 6.8$ & $15.2 \pm 8.6$ & $12.1 \pm 9.1$ & 0.681 \\
LIV tilt $\left(^{\circ}\right)$ & $22 \pm 5$ & $4 \pm 4$ & $4 \pm 3$ & $<0.01^{*}$ \\
UIVA $\left(^{\circ}\right)$ & $4 \pm 3$ & $2 \pm 2$ & $2 \pm 2$ & $<0.01^{*}$ \\
LIVA $\left(^{\circ}\right)$ & $7 \pm 5$ & $4 \pm 3$ & $5 \pm 4$ & 0.05 \\
\hline
\end{tabular}

$T L / L$ thoracolumbar or lumbar, $G C B$ global coronal balance, $A V T$ apical vertebral translation, $L I V$ lower instrumented vertebra, UIVA coronal upper instrumented vertebra, LIVA coronal lower instrumented vertebra

* Means significant difference of the parameters between pre-op and final follow-up 
Table 3 Comparison of preoperative, postoperative and final follow-up sagittal measurements

\begin{tabular}{lcccc}
\hline parameter & Pre-op & Post-op & Follow-up & $p$ \\
\hline T5-T12 sagittal $\left(^{\circ}\right)$ & $18 \pm 9$ & $24 \pm 8$ & $28 \pm 12$ & $<0.01^{*}$ \\
T10-L2 sagittal $\left(^{\circ}\right)$ & $8 \pm 8$ & $5 \pm 4$ & $7 \pm 5$ & 0.345 \\
L1-S1 sagittal $\left(^{\circ}\right)$ & $53 \pm 12$ & $56 \pm 10$ & $59 \pm 10$ & $0.038^{*}$ \\
UIVA sagittal $\left(^{\circ}\right)$ & $2 \pm 3$ & $1 \pm 2$ & $2 \pm 3$ & 0.319 \\
LIVA sagittal $\left({ }^{\circ}\right)$ & $13 \pm 7$ & $13 \pm 6$ & $14 \pm 7$ & 0.221 \\
GSB $(\mathrm{mm})$ & $31.0 \pm 23.5$ & $35.8 \pm 24.3$ & $21.8 \pm 16.8$ & $0.017^{*}$ \\
\hline
\end{tabular}

GSB global sagittal balance, UIVA sagittal upper instrumented vertebra, LIVA sagittal lower instrumented vertebra

* Means significant difference of the parameters between pre-op and final follow-up
Table 4 Comparison of maximal correction of TL/L curve between group $\mathrm{A}$ and $\mathrm{B}$

\begin{tabular}{lll}
\hline \multicolumn{2}{c}{ Immediate TL/L curve magnitude } \\
\cline { 2 - 3 } & $\leq 10^{\circ}$ & $>10^{\circ}$ \\
\hline Correction loss of thoracic curve & \\
$\mathrm{A}>5^{\circ}$ & 7 & 21 \\
$\mathrm{~B} \leq 5^{\circ}$ & 5 & 2 \\
Continuity correction $p=0.014$ & \\
\hline
\end{tabular}

and curve magnitude ratio (TL/L:T) $\geq 1.25$ as the indications for successful posterior selective TL/L fusion with pedicle screw constructs.

Undercorrection has been widely accepted in selective thoracic fusion. As stated by Von Lackum and Miller [20], it is desirable to achieve a correction of the primary thoracic curve that is not beyond the ability of the compensatory lumbar curve to balance the patient in selective thoracic fusion. When dealing with lumbar curves of a larger magnitude, the posterior approach, being capable of achieving strong corrective forces of the thoracic curve, is at risk of correcting the thoracic scoliosis beyond the capability of the lumbar curve to compensate and balance the spine in selective fusion for Lenke 1C [3, 21, 22]. Same perspectives had occurred in treatment for Lenke 5C curves. On one hand, for a balanced spine, complete correction of the instrumented curve was not suggested through anterior approach in Lenke 5C and a residual curve must be left to compensate the structural part of the thoracic curve [23]. But the definition of "residual" was not described. If the "residual" TL/L curve was too large, the spontaneous correction of thoracic curve would be incomplete and it may progress during follow-up. On the other hand, Huitema et al. [24] reported that spontaneous correction of the thoracic curve is a reflection of the TL/L curve correction in AIS in anterior selective TL/L fusion. It means, the more the $\mathrm{TL} / \mathrm{L}$ curve was corrected, the more the thoracic curve can spontaneously correct itself. But if the TL/L curve was corrected so much that the thoracic curve failed to compensate, decompensation may occur. So it is maximal TL/L curve correction to achieve better spontaneous correction for thoracic curve, or undercorrection to gain a balanced spine? A Chi-square test showed us that if the immediate postoperative curve magnitude of the TL/L curve (ILCM) was not more than $10^{\circ}$, the correction loss of the thoracic curve during the follow-up would be not more than $5^{\circ}$. The difference is statistical significant $(p=0.014)$. So we recommend the residual TL/L curve should be not more than $10^{\circ}$, approximately maximal correction, when treating moderate Lenke 5C curves. But for Lenke 5C curves that did not comply with our indication, undercorrection may be needed if selective TL/L fusion were performed. In this condition, achieving a balanced spine instead of better correction would be main purpose.

Adjacent disc wedging is the radiographic characteristic after anterior selective TL/L fusion, and the coronal UIVA and LIVA increased significantly at final follow-up $[7,18,25]$. Less fusion segments [26, 27] and more excessive compression of the convex side [25] in anterior procedure may explain this. Disc wedging was also noted after posterior procedure. Stasikelis et al. [28] suggested that overcorrection of the upper lumbar curve might explain the increased disc angle. Yu et al. [29] reported that posterior TL/L fusion could provide a better disc wedging compared to the anterior approach but with a longer fusion range. They found no significant difference in the disc wedging before and after surgery, and also between immediate post-operation and final follow-up. In present study, after posterior selective TL/L fusion the immediate coronal UIVA and LIVA decreased significantly (LIVA: $p=0.003$, UIVA: $p=0.001$, which is different from previous studies. The difference between immediate postoperation and final follow-up was statistically non-significant (LIVA: $p=0.333$, UIVA: $p=0.384$ ). Adjacent disc angle decreased after surgery and could be well maintained during the follow-up. The mechanism by which the discs become wedged is poorly understood. Endplate calcification has been observed in discs of humans with scoliosis and in a porcine model of induced scoliosis, and is 
considered as a possible cause of nutritional compromise and consequent disc degeneration and wedging in scoliosis [30-32]. But we did not do examinations on endplate calcification for patients with AIS routinely. Stokes et al. [32] reported that reduced mobility was a major source of disc changes and may be a factor in disc deformity. In the previous literature, posterior procedure fused more motion segments and reduced more mobility compared with anterior procedure. However, improvement of disc wedging was noted after posterior selective TL/L fusion. There was a conflict with Stokes' research. But their subjects were rat tails, which may be different from human spine. Moderate and flexible curves and better correction may explain behaviors of frontal UIVA and LIVA in the present study. Further investigations about the reason are still needed. In the process of rebalance, the changing of UIVA and LIVA are two major ways to remodeling the coronal alignment. They are the junctions of the grafted segment with the rest of the spine and will undergo considerable remodeling associated with re-equilibration of the whole spine after correction [23, 33]. Improvement and maintenance of LIVA and UIVA may mean better surgical outcomes and less re-equilibration.

Posterior selective thoracolumbar or lumbar fusion with pedicle screw constructs allows for spontaneous thoracic correction and maintains coronal and sagittal balance during the follow-up. Maximal correction instead of undercorrection was recommended for moderate Lenke 5C curves. Disc wedging could be improved after surgery and well maintained during the follow-up.

Acknowledgments IRB Approval Statement: This study has been approved from the Institutional Review Board.

\section{Compliance with ethical standards}

Conflict of interest The authors declare that they have no conflict of interest.

Ethical approval All procedures performed in studies involving human participants were in accordance with the ethical standards of the institutional and/or national research committee and with the 1964 Helsinki declaration and its later amendments or comparable ethical standards. For this type of study formal consent is not required.

Open Access This article is distributed under the terms of the Creative Commons Attribution 4.0 International License (http://creative commons.org/licenses/by/4.0/), which permits unrestricted use, distribution, and reproduction in any medium, provided you give appropriate credit to the original author(s) and the source, provide a link to the Creative Commons license, and indicate if changes were made.

\section{References}

1. Jansen RC, van Rhijn LW, Duinkerke E et al (2007) Predictability of the spontaneous lumbar curve correction after selective thoracic fusion in idiopathic scoliosis. Eur Spine $\mathrm{J}$ 16(9):1335-1342. doi:10.1007/s00586-007-0320-3

2. Wang Y, Bunger CE, Zhang Y et al (2012) Postoperative spinal alignment remodeling in Lenke $1 \mathrm{C}$ scoliosis treated with selective thoracic fusion. Spine J 12(1):73-80. doi:10.1016/j.spinee. 2011.10.024

3. Edwards CN, Lenke LG, Peelle M et al (2004) Selective thoracic fusion for adolescent idiopathic scoliosis with $\mathrm{C}$ modifier lumbar curves: 2- to 16-year radiographic and clinical results. Spine (Phila Pa 1976) 29(5):536-546

4. Hee HT, Yu ZR, Wong HK (2007) Comparison of segmental pedicle screw instrumentation versus anterior instrumentation in adolescent idiopathic thoracolumbar and lumbar scoliosis. Spine (Phila Pa 1976) 32(14):1533-1542. doi:10.1097/BRS.0b013e318 067dc3d

5. Geck MJ, Rinella A, Hawthorne D et al (2009) Comparison of surgical treatment in Lenke $5 \mathrm{C}$ adolescent idiopathic scoliosis: anterior dual rod versus posterior pedicle fixation surgery: a comparison of two practices. Spine (Phila $\mathrm{Pa}$ 1976) 34(18):1942-1951. doi:10.1097/BRS.0b013e3181a3c777

6. Tao F, Wang Z, Li M et al (2012) A comparison of anterior and posterior instrumentation for restoring and retaining sagittal balance in patients with idiopathic adolescent scoliosis. J Spinal Disord Tech 25(6):303-308. doi:10.1097/BSD.0b013e31822 $04 \mathrm{c} 3 \mathrm{e}$

7. Li M, Ni J, Fang X et al (2009) Comparison of selective anterior versus posterior screw instrumentation in Lenke5C adolescent idiopathic scoliosis. Spine (Phila Pa 1976) 34(11):1162-1166. doi:10.1097/BRS.0b013e31819e2b16

8. Sweet FA, Lenke LG, Bridwell KH et al (2001) Prospective radiographic and clinical outcomes and complications of single solid rod instrumented anterior spinal fusion in adolescent idiopathic scoliosis. Spine (Phila Pa 1976) 26(18):1956-1965

9. Shufflebarger HL, Geck MJ, Clark CE (2004) The posterior approach for lumbar and thoracolumbar adolescent idiopathic scoliosis: posterior shortening and pedicle screws. Spine (Phila $\mathrm{Pa}$ 1976) 29(3):269-276

10. Lenke LG, Betz RR, Harms J et al (2001) Adolescent idiopathic scoliosis: a new classification to determine extent of spinal arthrodesis. J Bone Joint Surg Am 83-A(8):1169-1181

11. Schmid SL, Buck FM, Boni T et al (2016) Radiographic measurement error of the scoliotic curve angle depending on positioning of the patient and the side of scoliotic curve. Eur Spine J 25(2):379-384. doi:10.1007/s00586-015-4259-5

12. Morrissy RT, Goldsmith GS, Hall EC et al (1990) Measurement of the Cobb angle on radiographs of patients who have scoliosis. Evaluation of intrinsic error. J Bone Joint Surg Am 72(3): 320-327

13. Brown JC, Axelgaard J, Howson DC (1984) Multicenter trial of a noninvasive stimulation method for idiopathic scoliosis. A summary of early treatment results. Spine (Phila Pa 1976) 9(4):382-387

14. Brooks HL, Azen SP, Gerberg E et al (1975) Scoliosis: a prospective epidemiological study. J Bone Joint Surg Am 57(7):968-972

15. Lonstein JE, Carlson JM (1984) The prediction of curve progression in untreated idiopathic scoliosis during growth. J Bone Joint Surg Am 66(7):1061-1071

16. Sanders AE, Baumann R, Brown $\mathrm{H}$ et al (2003) Selective anterior fusion of thoracolumbar/lumbar curves in adolescents: when can the associated thoracic curve be left unfused? Spine (Phila Pa 1976) 28(7):706-714. doi:10.1097/01.BRS.0000051925.88443. 85

17. Ogilvie JW (1988) Anterior spine fusion with Zielke instrumentation for idiopathic scoliosis in adolescents. Orthop Clin North Am 19(2):313-317 
18. Lark RK, Yaszay B, Bastrom TP et al (2013) Adding thoracic fusion levels in Lenke 5 curves: risks and benefits. Spine (Phila Pa 1976) 38(2):195-200. doi:10.1097/BRS.0b013e3182634c85

19. Li M, Fang X, Sun Y et al (2011) Thoracic curve correction after posterior fusion and instrumentation of structural lumbar curves in patients with adolescent idiopathic scoliosis. Arch Orthop Trauma Surg 131(10):1375-1381. doi:10.1007/s00402-011-13207

20. Von Lackum WH, Miller JP (1949) Critical observations of the results in the operative treatment of scoliosis. J Bone Joint Surg Am 31A(1):102-106

21. Dobbs MB, Lenke LG, Walton T et al (2004) Can we predict the ultimate lumbar curve in adolescent idiopathic scoliosis patients undergoing a selective fusion with undercorrection of the thoracic curve? Spine (Phila Pa 1976) 29(3):277-285

22. Yong MR, Izatt MT, Adam CJ et al (2012) Secondary curve behavior in Lenke type 1C adolescent idiopathic scoliosis after thoracoscopic selective anterior thoracic fusion. Spine (Phila $\mathrm{Pa}$ 1976) 37(23):1965-1974. doi:10.1097/BRS.0b013e3182583421

23. Wang T, Zeng B, Xu J et al (2008) Radiographic evaluation of selective anterior thoracolumbar or lumbar fusion for adolescent idiopathic scoliosis. Eur Spine J 17(8):1012-1018. doi:10.1007/ s00586-007-0510-z

24. Huitema GC, Jansen RC, van Ooij A et al (2013) Predictability of spontaneous thoracic curve correction after anterior thoracolumbar correction and fusion in adolescent idiopathic scoliosis. A retrospective study on a consecutive series of 29 patients with a minimum follow-up of 2 years. Spine J. doi:10.1016/j.spinee. 2013.06.013

25. Satake K, Lenke LG, Kim YJ et al (2005) Analysis of the lowest instrumented vertebra following anterior spinal fusion of thoracolumbar/lumbar adolescent idiopathic scoliosis: can we predict postoperative disc wedging? Spine (Phila Pa 1976) 30(4):418-426
26. Betz RR, Harms J, Clements DR et al (1999) Comparison of anterior and posterior instrumentation for correction of adolescent thoracic idiopathic scoliosis. Spine (Phila $\mathrm{Pa}$ 1976) 24(3):225-239

27. Lowe TG, Betz R, Lenke L et al (2003) Anterior single-rod instrumentation of the thoracic and lumbar spine: saving levels. Spine (Phila Pa 1976) 28(20):S208-S216. doi:10.1097/01.BRS. 0000092483.10776.2A

28. Stasikelis PJ, Miller WD, Wilson C et al (2002) Spine behavior caudal to instrumentation in King II and IV curves. Clin Orthop Relat Res 400:132-139

29. Yu B, Wang YP, Qiu GX et al (2010) Postoperative disc wedging in adolescent idiopathic thoracolumbar/lumbar scoliosis: a comparison of anterior and posterior approaches. Chin Med Sci J 25(3):156-161

30. Laffosse JM, Odent T, Accadbled F et al (2010) Micro-computed tomography evaluation of vertebral end-plate trabecular bone changes in a porcine asymmetric vertebral tether. J Orthop Res 28(2):232-240. doi:10.1002/jor.20974

31. Roberts S, Caterson B, Evans H et al (1994) Proteoglycan components of the intervertebral disc and cartilage endplate: an immunolocalization study of animal and human tissues. Histochem J 26(5):402-411

32. Stokes IA, McBride C, Aronsson DD et al (2011) Intervertebral disc changes with angulation, compression and reduced mobility simulating altered mechanical environment in scoliosis. Eur Spine J 20(10):1735-1744. doi:10.1007/s00586-011-1868-5

33. Lu WC, Zhang JG, Qiu GX et al (2009) Selective anterior thoracolumbar or lumbar fusion for adolescent idiopathic scoliosis. Zhonghua Wai Ke Za Zhi 47(10):758-761 